\title{
WestVirginiaUniversity
}

THE RESEARCH REPOSITORY @ WVU

Graduate Theses, Dissertations, and Problem Reports

2011

\section{Apical Leakage of a New Root Canal Sealer}

\author{
Nathan E. Beam \\ West Virginia University
}

Follow this and additional works at: https://researchrepository.wvu.edu/etd

\section{Recommended Citation}

Beam, Nathan E., "Apical Leakage of a New Root Canal Sealer" (2011). Graduate Theses, Dissertations, and Problem Reports. 3303.

https://researchrepository.wvu.edu/etd/3303

This Thesis is protected by copyright and/or related rights. It has been brought to you by the The Research Repository @ WVU with permission from the rights-holder(s). You are free to use this Thesis in any way that is permitted by the copyright and related rights legislation that applies to your use. For other uses you must obtain permission from the rights-holder(s) directly, unless additional rights are indicated by a Creative Commons license in the record and/ or on the work itself. This Thesis has been accepted for inclusion in WVU Graduate Theses, Dissertations, and Problem Reports collection by an authorized administrator of The Research Repository @ WVU. For more information, please contact researchrepository@mail.wvu.edu. 


\title{
Apical Leakage of a New Root Canal Sealer
}

\author{
Nathan E. Beam \\ Thesis Submitted to the \\ School of Dentistry \\ At West Virginia University \\ in partial fulfillment of the requirements \\ for the degree of \\ Master of Science \\ In \\ Endodontics \\ C. Russell Jackson, DDS, MS
Michael Bagby, DDS, MS
Thomas Razmus, DDS, MS
}

Department of Endodontics

Morgantown, West Virginia

2011

Keywords:

iRoot SP, Single Cone, Dye Leakage 


\title{
ABSTRACT \\ Apical Leakage of a New Endodontic Root Canal Sealer
}

\author{
Nathan E. Beam
}

A new endodontic root canal sealer, iRoot SP, has been introduced. This bioceramic root canal sealer claims to be a superior sealing and filling material for root canals. Although the manufacturer advocates the use of a single cone technique with this sealer, they state that it may also be used with lateral compaction and warm vertical condensation. The purpose of this study was to compare in vitro apical microleakage of iRoot SP root canal sealer to AH Plus sealer when used in conjunction with a single cone technique and lateral compaction technique.

Eighty six mesial roots of mandibular molar teeth with mature apices were randomly divided into four experimental groups along with a positive and negative control groups. Teeth were cleaned and sectioned at the CEJ with high speed hand piece and water coolant. All teeth were pre-flared with $\mathrm{S} 1$ and S2 Protaper Universal (DENTSPLY ${ }^{\circledR}$ ) NiTi rotary files. Then the teeth were instrumented to a \#30 .06 taper master apical file with Brasseler ${ }^{\circledR}$ Endosequence Niti rotary files in a crown down technique. Teeth were then divided into the groups: Group A- lateral condensation technique with iRoot Sp, Groups B- lateral condensation with AH Plus, Group C- single cone technique with iRoot SP, Group Dsingle cone with AH Plus, positive control (obturation with no sealer), and negative control (no obturation with two layers of varnish covering entire root). Teeth were allowed to soak in $1 \%$ methylene blue dye under vacuum (390 torr) and for an additional 7 days once the seal was broken. The clearing process consisted of 24 hours in 5\% nitric acid, 24 hours in 80\% ethyl alcohol, 24 hours in $99.8 \%$ ethyl alcohol, and the roots became transparent after 48 hours in $99 \%$ methyl salicylate. Two second year endodontic residents along with a dental hygienist graded the apical dye penetration a measuring microscope.

None of the negative controls showed any leakage and all of the positive control showed leakage the entire length of the root. Of the 86 specimens starting the study, 4 did not clear properly and were excluded from the study leaving a total of 82 . In the iRoot SP group, the mean apical leakage in group $A$ was $0.83 \mathrm{~mm}+/-0.15$, and $0.63 \mathrm{~mm}+/-0.13$ for group $C$. In the AH Plus group, the mean apical leakage was $1.63 \mathrm{~mm}+/-0.13$ in group $B$, and $0.42 \mathrm{~mm}+/-0.14$ in group $D$.

Comparable levels of apical leakage were found between iRoot SP (single cone and lateral compaction) and AH plus single cone. AH plus with lateral compaction had statistically more apical dye leakage that the other groups. None of the negative controls showed any leakage and all of the positive controls demonstrated leakage supporting the experimental design. This in vitro study supports the use of the sealers AH Plus or iRoot SP in combination with .06 taper gutta-percha points in the obturation of .06 canal preparations. 


\section{TABLE OF CONTENTS}

Title Page

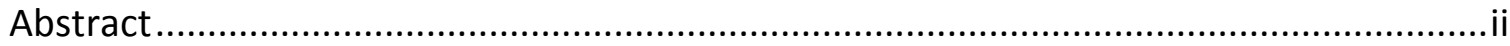

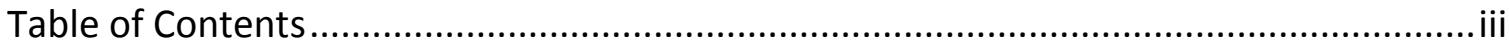

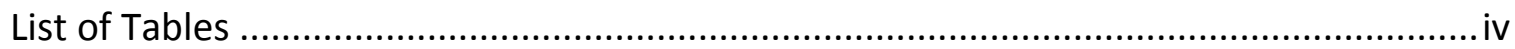

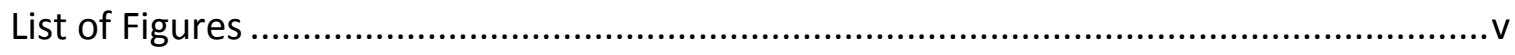

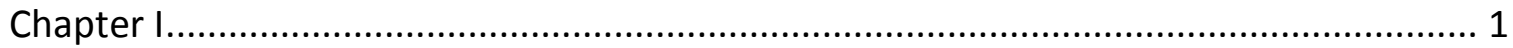

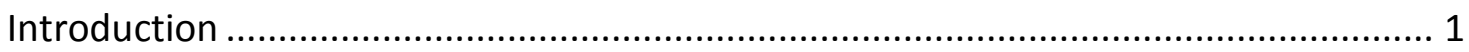

Statement of the Problem ................................................................................... 2

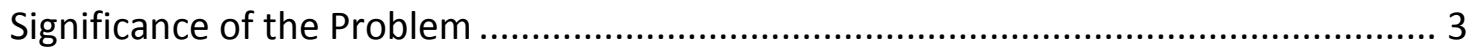

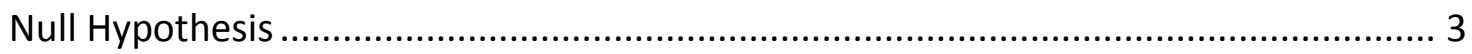

Definition of Terms

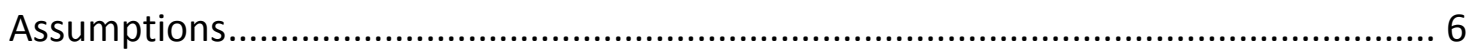

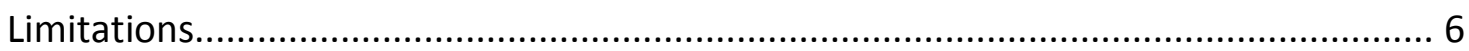

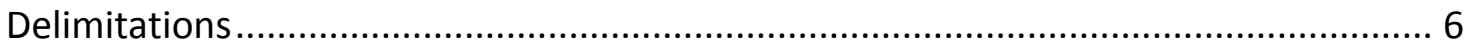

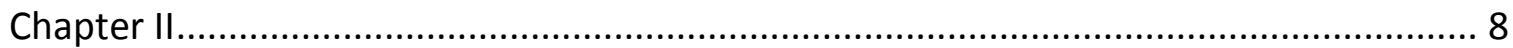

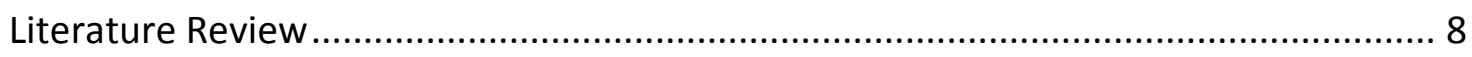

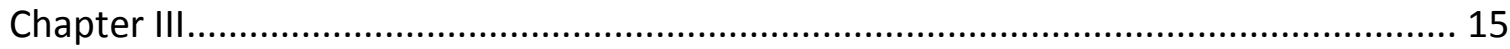

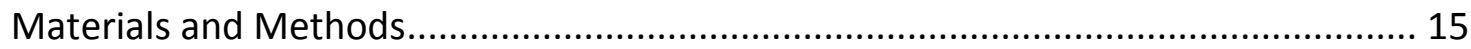

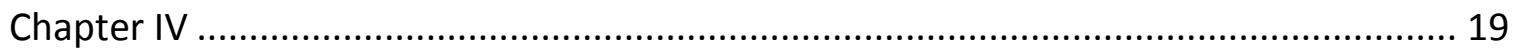

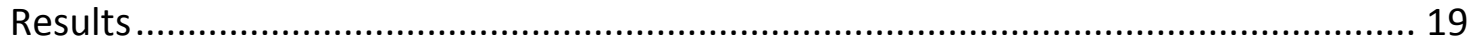

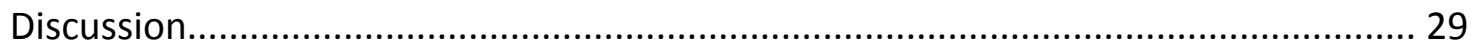

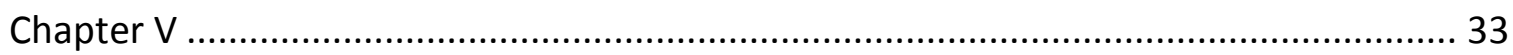

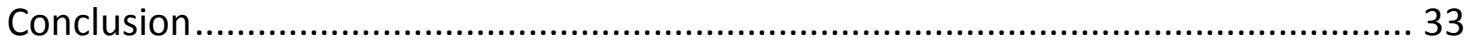

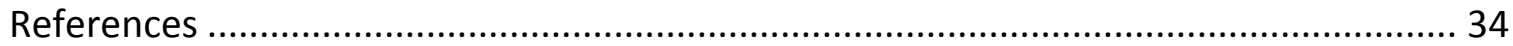




\section{LIST OF TABLES}

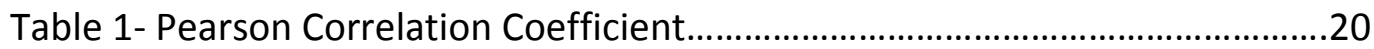

Table 3- Tukey's Honestly Significant Difference.................................................23

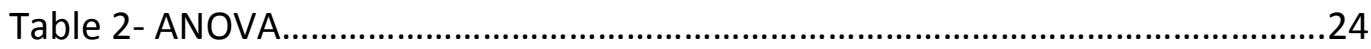




\section{LIST OR FIGURES}

Figure 1- Mean Value of linear Dye Penetration..............................................................21

Figure 2- Mean value of Linear Dye Penetration................................................................22

Figure 3- Group A- Dye Penetration by Grader..................................................................25

Figure 4- Group B- Dye Penetration by Grader................................................................26

Figure 5- Group C- Dye Penetration by Grader..................................................................27

Figure 6- Group D- Dye penetration by Grader.............................................................28 


\section{Chapter I}

\section{INTRODUCTION}

One of the primary objectives of conventional endodontic therapy is to achieve the total obturation of the root canal space. However, incomplete obturation of the root canal system still accounts for nearly $60 \%$ of all endodontic failures $(1,2)$. According to Weine (3), the most common cause of endodontic failure can be attributed to the lack of an adequate apical seal. Over the years, many different obturation techniques have been tested and utilized in hopes of increasing the quality of the apical seal.

Lateral condensation of gutta-percha is at present the most widely used method of obturation (4), and in a survey of Diplomates of the American Board of Endodontics, Taintor and Ross (5) found that the majority of respondents considered lateral condensation to be the preferred method of obturation. Lateral condensation provides an apical seal that is as good or better than numerous other obturation techniques, and this has been consistently proven over the years $(6,7,8,9,10$, and 11$)$. Advantages to this technique include predictability, relative ease of use, conservative preparations, and controlled placement of materials. Even when performed properly, the primary disadvantage to lateral condensation is the inability to adapt the mass of gutta-percha to the cul-de-sacs, fins, and accessory and lateral canals of the root canal system. For this reason, lateral condensation, in common with all other obturation techniques, must use a root canal sealer to obtain a fluid tight seal. This fact is supported by numerous studies, all of which have clearly demonstrated that a sealer must be used in 
conjunction with all obturation techniques, thus improving the apical seal significantly $(9,12$, $13,14)$.

Root canal sealers are used to fill any irregularities between the mass of the guttapercha filling material and the prepared canal walls. A sealer also functions as a lubricant during placement of the gutta-percha within the main canal and may fill accessory canals or multiple foramina. Currently, there are no sealers that possess all of the optimal properties required to be considered an ideal root canal sealer. A new obturation sealer, iRoot SP root canal sealer (Innovative Biocreamix Inc, Vancouver, Canada and marketed as BC sealer by Endosequence in the USA) has been introduced. According to the manufacturer's description, iRoot SP is a convenient, premixed, ready-to-use injectable, white, hydraulic cement paste developed for permanent root canal fillings. iRoot SP is an insoluble, radiopaque, aluminum free material based on a calcium silicate composition, which requires the presence of water to set and harden. The makers of iRoot SP claim it to be superior to all other sealers in fulfilling the requirements of "the ideal root canal sealer".

\section{STATEMENT OF THE PROBLEM}

Is there is a difference in the apical leakage of a single cone obturation in combination with iRoot SP sealer when compared to lateral compaction with AH Plus sealer? 


\section{SIGNIFICANCE OF THE PROBLEM}

One of the most commonly used ways to obturate the root canal space is the lateral condensation of gutta-percha. This technique, in combination with AH Plus sealer, has been proven to provide an optimal apical seal with clinically acceptable apical leakage when completed correctly. Short falls of the technique are: (1) the inability to compact gutta-percha to within several millimeters in curved roots; (2) compaction forces may cause vertical root fractures(VRF); and (3) sealer shrinkage, which may lead to a compromised apical seal.

The manufacturer of iRoot SP claims the sealer to be user-friendly, biocompatible, antibacterial, with no shrinkage, with small particle size that allows it to flow into all cul-de-sacs, fins and accessory canals with a single gutta-percha master cone. If these characteristics are true, it will make the procedure more successful with less time required to accomplish the stated goals.

\section{NULL HYPOTHESIS}

There is no significant difference in apical leakage between iRoot SP sealer (single cone) and $\mathrm{AH}$ Plus sealer (lateral condensation).

\section{DEFINITION OF THE TERMS}


Actual tooth length: The measured length, from the reference point, of a file placed in the canal until its tip becomes visible at the apical foramen using 3.5X magnification.

Cold lateral condensation: An obturation technique which involves the placement of sealer in the canal, followed by a measured master gutta-percha point, which is laterally condensed by a spreader to make room for additional gutta-percha points.

Crown down technique: A technique of canal instrumentation which enlarges the coronal portion of the canal in the initial stages of mechanical preparation. The canal is enlarged in a step-wise fashion from the coronal orifice towards the apical foramen with progressively smaller files until the desired length is achieved.

Leakage: A qualitative description of the presence of methylene blue dye coronal to the end point of the gutta-percha, as visualized microscopically.

Linear apical leakage: A quantitative measurement of the maximum penetration of the dye from the apical endpoint of the master gutta-percha cone, in the coronal direction.

Reference point: A repeatebly reproducibly recognized flat landmark identified at the coronal orifice created when the tooth is sectioned at the CEJ.

Rotary instrumentation: A technique of canal instrumentation which utilizes an engine driven handpiece to rotate endodontic files in a 360 degree clockwise direction.

Single cone obturation: Obturation of the canal space utilizing a single gutta-percha cone that is manufactured to be the same size as the largest file used to the apex, along with an endodontic sealer. 
Taper: A descriptive term for the smooth increase in diameter of a conical object from its smallest diameter to its largest diameter.

Working length: (WL), The length determined by subtracting $1.0 \mathrm{~mm}$ from the actual tooth length.

Master Apical File: (MAF), The largest file used at the working length to clean and shape the canal.

Apical percolation: Bacteria and/or byproducts that are able to pass through the obturation material at the apex of an endodontically treated tooth. 


\section{ASSUMPTIONS}

1) Lateral condensation of gutta-percha is the most commonly used technique. 2) The lateral condensation technique results in a clinically acceptable apical seal. 3) All sealers have some degree of shrinkage. 4) AH Plus has been shown to posses equal to or superior sealing abilities than other commonly used sealers. 5) Apical leakage causes apical periodontitis. 6) Single cone obturation technique is easier and quicker than cold lateral condensation techniques. 7) An apical dye leakage study is an appropriate indicator of the quality of the apical seal.

\section{LIMITATIONS}

1) An in vitro experiment is simulating an in vivo situation.

2) There is a human element in performing these techniques.

3) The root canals used will be similar, but will not have identical morphology.

4) Individual root canal system variability could affect the instrumentation and obturation quality of any given tooth.

\section{DELIMITATIONS}

1) The extracted teeth were selected carefully in an attempt to minimize variability.

2) Mesial buccal roots of mandibular molars where selected

3) Selected teeth had completely formed apices 
4) Any tooth which allowed a \#30.02 taper ISO file to pass through the apical foramen was eliminated.

5) Teeth were sectioned at the CEJ to allow optimal straight line access.

6) All instrumentation and obturation were performed by the principal investigator.

7) Sealer was allowed to set for 72 hours in a $100 \%$ humidity environment.

8) Apical leakage was determined after the teeth were suspended in methylene blue dye under vacuum for 24 hours and an additional 7 days after the seals broken.

9) A clearing method was used to visualize the dye leakage using a measuring microscope.

10) Measurements of leakage will be done independently by two second year endodontic residents and a dental hygienist without knowledge from which experimental group each tooth originated. 


\section{CHAPTER II}

\section{REVIEW OF LITERATURE}

The goal of endodontic therapy is the complete cleaning and shaping of the root canal system, development of a fluid tight seal the entire length of the system, and complete obliteration of the root canal space. It is impossible to remove all toxins through debridement alone due to fins and deltas associated with most root canal systems (15). Any bacteria or toxins left in the canal must be isolated by obturation so that they are prevented from reaching the periapical tissues. The apical seal must prevent leakage between the root canal system and the periapical tissues in order to prevent bacteria from using the available fluid as a substrate (16). The seal obtained during obturation must also be protected from coronal microleakage. Coronal microleakage has been found to be an important factor in endodontic success $(17,18)$.

The overall success rate for endodontic therapy is dependent on several factors including, but not limited to, placement of root canal fillings in relation to the anatomical apex, canal sealing ability of technique and material, and quality of coronal restoration. Swartz et al reported an overall success rate of $90 \%$ in his study. He evaluated over 1000 teeth, clinically and radiographically, in a twenty year retrospective study, concluding that overfilled canals were four times more likely to result in failure than canals filled short of the radiographic apex (17). According to Ingle, the most common cause of endodontic failure is apical percolation caused by incomplete obturation. The "Washington study" showed that $59 \%$ of endodontic failures were due to incomplete obturation (18). Barbakow found an overall success rate of 
$87 \%$, with short fills slightly less successful (76\%) than overfills (82\%) (19). Morse found an overall success rate of $95 \%$ and concluded that flush fills and overfills were more successful that underfills (20).

Although the apical seal is important, the long-term success or failure of endodontic treatment depends to a large degree on the quality of the coronal restoration and the reduction of bacteria during the cleaning and shaping phase. Swartz reported that endodontic failure was twice as likely to occur when an inadequate coronal restoration was present (17). Ray and Trope determined that the most important factor for endodontic success is not the quality of the endodontic treatment, but the quality of the coronal restoration. They examined the radiographs of over 1000 teeth that had been treated endodontically and concluded that radiographic evidence of periapical inflammation was present less often when there was a combination of good root canal therapy with a good coronal restoration. Teeth with well performed endodontic therapy that were restored with a poor coronal restoration had more periapical inflammation than teeth with poor endodontic therapy and good coronal restoration (21).

Currently in endodontics, gutta percha is used in conjunction with an endodontic sealer to obturate the root canal system. The gutta-percha is used to fill the large space in the canal and to force the sealer into the fins, apical deltas, and lateral canals. Cold lateral condensation of gutta-percha is the most common obturation technique. Advantages of this technique include its predictability, length control, and ease of use. Disadvantages include the inability to produce a homogenous mass, potential void when accessory cones do not reach the depth of 
spreader penetration, and less adaptation to canal irregularities (22). Lateral condensation is often used as a control for evaluating the sealing ability of new obturation techniques (23).

The conventional root-filling technique taught in most dental schools has been the cold lateral condensation technique using an ISO .02 tapered, standardized gutta-percha point as the master cone, supplemented with accessory cones $(24,25)$. However, many practitioners considered this method time consuming and technique sensitive.

The single-cone technique, on the other hand, is faster and easier to perform. However, single-cone techniques performed with conventional sealers have been perceived to be less effective in sealing root canals than the gutta-percha warm vertical compaction technique (26). The single cone method has gained popularity in some European countries (27) but has been considered inferior to the lateral compaction technique as described in some textbooks (28). Some in vitro studies on dye penetration along root fillings have shown that the single-cone technique permitted more leakage than the cold lateral technique $(26,29)$, whereas others using a leakage technique with fluid movement did not find a difference after root filling of oval-shaped canals (30). Results from an in vivo study showed no significant difference in treatment outcome between single-cone and lateral compaction techniques after 6 to 18 months (35).

In these previous studies, shaping of the root canals was performed by hand instrumentation with stainless-steel instruments. However, noncompaction, single-cone filling of root canals has recently been revived $(32,33)$ with the introduction of "greater taper" 
master cones that closely match the geometry of nickel-titanium instrumentation systems (34). Preparation of the root canal with rotary nickel-titanium ( $\mathrm{Ni}-\mathrm{Ti}$ ) instruments may improve the adaptation between gutta-percha point and the canal wall because the flexible $\mathrm{Ni}-\mathrm{Ti}$ instruments may result in less straightening and flaring of curved canals compared with the use of stainless steel instruments $(35,36,37,38,39)$. The use of rotary instruments may also improve preparation of a uniformly round space compared with circumferential filling produced with hand instruments, although the cleaning efficacy, however, may depend on canal morphology $(40,41$, and 42). Thus, a .06 taper single-cone technique used after canal preparation with .06 tapered rotary instruments was found to be comparable to lateral compaction in a recent laboratory study on simulated canals and mesiobuccal maxillary molar canals (33). The advent of contemporary root canal sealing systems that claim to create bonds along the sealer-guttapercha interface by modifications of the sealer or the root-filling material may also support the use of a single-cone obturation technique (43).

It has been shown in several studies that the use of a sealer with gutta-percha significantly increases the apical sealing abilities of all techniques $(9,12,13,14)$. Before a root canal sealer can be considered for use, it must possess certain desirable characteristics. Grossman (44) identified eleven requirements for the ideal root canal sealer. The root canal sealer should: 1) provide an excellent seal when set; 2) produce adequate adhesion between the sealer, the canal wall, and the filling material; 3) be radiopaque; (4) be nonstaining; (5) be dimensionally stable; (6) be easily mixed and introduced into the canal; (7) be easily removed if necessary; (8) be insoluble in tissue fluids; (9) be bactericidal or discourage bacterial growth; 
(10) be non-irritating to periapical tissue; (11) be slow setting, to ensure sufficient working time. Currently none of the available endodontic sealers have all eleven characteristics (45). Although none of the root canal sealers currently available possess all of the ideal properties, there are many which function adequately with respect to clinical performance. One of the commonly used control sealers that have been used in many apical leakage studies is $\mathrm{AH}$ Plus $(46,47,48)$. AH Plus is an epoxy resin cement that has been proven to be acceptable. It has been shown to have superior or equal apical sealing ability when tested against other commonly used sealers $(47,48)$.

Even though there are currently several acceptable endodontic sealers available, there is a continuous search for newly developed products that are improved and more predictable than existing ones. Bioceramic obturation materials are the latest addition to the dentist's arsenal. The science associated with bioceramic technology has helped to develop several biocompatible ceramic material used in dentistry and medicine. Research of ceramics for the use in biomedical applications began in the early 1970's, and for the past forty years, the application of ceramics in biomedicine has been expanding(49). "Bioceramics" are composed of alumina and zirconia, bioactive glass, glass ceramic, calcium silicates, coatings and composites, hydroxapatite and resorbable calcium phosphates, and radiotherapy glasses $(50,51,52)$. Bioceramics are currently being used in orthopedics in applications such as joint or tissue replacement, and for coating implants for improving biocompatibility. Bone defects are being filled with porous ceramics such as calcium phosphate. In dentistry, calcium silicates (MTA) are being used with great biocompatibility, sealablity, and success(53). 
iRoot SP is a new bioceramic endodontic sealer, with some of the advantages claimed by the manufacturer(Endosequence BC Sealer) to be: (1) enhanced biocompatibility, (2) no shrinkage, (3)non-resorbable (which is critical for a one-cone technique), (4) high pH (12.8) during the initial 24 hours of the setting process (which is strongly anti-bacterial), (5) excellent sealing ability, (6) quick setting time ( 3 to 4 hours) and (7) ease of use (particle size is small enough to allow for use in a syringe). The high $\mathrm{pH}$ makes this material very antibacterial during its setting period (the $\mathrm{pH}$ decreases over the following days). This is an important physical property for a dental cement, particularly if it is being used as an endodontic sealer (53). In another study by Zhang et al (46), it was noted that the BC Sealer (iRoot SP) killed all bacteria within 2 minutes of contact. The authors proceed to opine that the antibacterial effect might be a combination of high $\mathrm{pH}$, hydrophilicity, and active calcium hydroxide diffusion (46). There is very little literature on the new endodontic sealer, but if current claims are true, iRoot SP should have equal or better apical sealing properties when compared to the other commonly used sealers, with the added advantage of having additional biocompatible characteristics. Permeability of the apical seal has been previously demonstrated by dye penetration $(54,55)$, radioisotope penetration $(56,57)$, electrochemical means $(58)$, microbiological invasion (59), fluorometric measurements (60), and scanning electron microscopic examination(61). Evaluation of dye penetration continues to be a commonly used technique to assess the quality of the apical seal. Matloff found that a dye penetrated farther coronally than did radioisotopes (62). Studies have suggested that a vacuum must be applied to remove any trapped air inside the canal which could hinder the penetration of a dye $(63,64)$. Kersten and Moorer found that dyes used to evaluate leakage contain much smaller particles than the average bacteria size 
associated with endodontics. They summarized that microleakage of small particles is unlikely to play a role in periapical disease, but leakage of high molecular weight substances of bacteriasized particles is an important factor (65). Hovland and Dumsha concluded that all root canal sealers leak to some degree. They believe that there is a critical level of leakage that is unacceptable for healing, and failure to achieve an adequate seal results in endodontic failure. Leakage may occur at the interface of the dentin and sealer, at the interface of the semisolid core and sealer, through the sealer itself, or by complete or partial dissolution of the sealer (66).

Dye penetration has been examined by several methods of visualization. Eldeeb suggested that the longitudinal sectioning of roots would not allow the examiner to measure leakage accurately, and that the examiner could get a false impression of under-penetration unless the plane of sectioning reveals the area of deepest penetration (67). Cross-sectioning of the root has been utilized in several leakage studies (68). A disadvantage of this technique is that tooth structure is lost during cutting of the root and measurement of maximum penetration could again be incorrect. Robertson developed a clearing technique which was slightly altered by Roda and Gutmann $(69,70)$. This technique allows the microscopic visualization of dye penetration around the circumference of the entire canal. 


\section{CHAPTER III}

\section{MATERIAL AND METHODS}

Eighty-six mesial roots of human mandibular molar teeth with mature apices were assigned to four experimental groups along with positive and negative control groups. The teeth were cleaned of extraneous tissue and calculus and then stored in $5.25 \% \mathrm{NaOCl}$ for 24 hours to dissolve any soft tissue remaining on the root surface. Crowns of the teeth were sectioned at the CEJ with a high speed hand piece with a \#1958 carbide bur ( Midwest burs ${ }^{\circledR}$ ) with continuous water spray. A \#15 K-file (KontrolFlex series II by Brasseler USA ${ }^{\circledR}$ ) was used to locate the apical foramen and $1.0 \mathrm{~mm}$ was subtracted from the actual root canal length to determine the working length.

The coronal and middle thirds of operated canals were first flared utilizing Protaper ${ }^{\circledR}$ (Tulsa Dental Specialties) Shaping file 1 and Shaping file 2 (both rotary files were used to the working length). To ensure patency of the apical foramen through out the procedure a \#15 Kfile was passed through the apical foramen after the use of each rotary file size. Sodium hypochlorite (5.25\%) was used as the irrigant and was delivered into the canal with 5cc Luer Lok syringe, with constant flushing and suction, and was left in the canal during all instrumentation. All teeth were instrumented to master apical file (MAF) of \#30 with Endosequence ( by Brasseler USA ${ }^{\circledR}$ ) .06 taper nickel titanium rotary files in a crown down technique. All teeth were dried with paper point until no signs of moisture were apparent on the paper point. 


\section{Obturation of the canals}

Teeth were randomly assigned to four groups of twenty. Three teeth were set aside for a negative control group and another three for the positive control group.

Group A: Lateral condensation technique with iRoot SP sealer. Prior to master cone placement sealer was delivered to the coronal two thirds of the canal according to manufacturer's instructions. The apical half of each .04 taper Bioceramic gutta-percha master cone (Brasseler ${ }^{\circledR}$ Endosequence) was coated with sealer, placed in the canal, and slow placed to working length. A \#30 spreader was inserted into the canal 1-2 $\mathrm{mm}$ short of working length and lateral condensation was carried out in the normal manner until the entire canal was satisfactorily obturated.

Group B: Lateral condensation technique with AH Plus sealer. The specimens in group B were obturated in a similar manner as in group A, but with AH Plus as the sealer.

Group C: Single cone technique with iRoot SP sealer. Canals were obturated with a single .06 taper Bioceramic gutta-percha master cone ( Brasseler ${ }^{\circledR}$ Endosequence) that matched the last file size used in the instrumentation of the canal. Next, iRoot SP was injected into the coronal two thirds as per manufacturer's instructions. The apical half of the prefitted master cone was coated with sealer and introduced into the canal and slowly placed to working length.

Group D: Single cone technique with AH Plus sealer. The canals in group D were obturated in a similar manner as in group C, but with AH Plus as the sealer. 
Positive control: Canals were obturated with gutta-percha in a lateral condensation technique without sealer.

Negative control: Canals were not obturated, but the entire roots were covered with two layers of nail polish.

After obturation the gutta-percha was seared off $3 \mathrm{~mm}$ below access opening, which was then sealed with Permaflo ${ }^{\circledR}$ Purple anatomical indicating composite by ultradent. All specimens were stored in a humidor for 72 hours with $100 \%$ humidity at room temperature to allow the sealer to set. Teeth were allowed to air dry and then coated with nail polish except for the apical 1-2 mm of the root. The roots were immersed in $1 \%$ methylene blue dye solution and then were placed under a vacuum pressure of 390 torr for 24 hours. The specimens were allowed to soak for 7 more days in the dye solution after the vacuum was broken. Next, the roots were rinsed with saline and the nail polish was removed with acetone. The specimens were then stored in saline until the clearing process.

\section{CLEARING PROCESS}

All teeth were cleared for evaluation using a technique described by Roda and Gutmann. Specimens were placed in $5 \%$ nitric acid for 24 hours to decalcify the roots. The roots were then dehydrated by being placed in $80 \%$ ethyl alcohol for 24 hours followed by 24 hours in $99.8 \%$ ethyl alcohol. Clearing of the roots was accomplished by covering the entire specimens in methyl salicylate. Roots became transparent after 48 hours in the $99 \%$ methyl salicylate. The specimens were then stored in the methyl salicylate until evaluated for dye 
penetration. Each container was numbered in a manner so that the graders could not identify which group they were in.

\section{DATA COLLECTION}

Two second year endodontic residents and one dental hygienist independently evaluated leakage using a measuring microscope at 15x power. Linear measurements were made, to the nearest $0.01 \mathrm{~mm}$, from the apical terminus of the gutta-percha to the most coronal extent of the dye penetration. Each investigator recorded the measurements on a data collection sheet as shown in appendix A. A measurement of $0.00 \mathrm{~mm}$ indicated no leakage coronal to the endpoint of the gutta-percha, and $15 \mathrm{~mm}$ was indicated if leakage penetrated the entire length of the root.

\section{STATISTICS}

Pearson test was used to determine if difference existed between graders. Differences between groups were analyzed with ANOVA and Tukey HSD (Honestly Significant Difference) test using JMP8 software (SAS Institute, Cary, NC) at alpha of 0.05. 


\title{
CHAPTER IV
}

\author{
RESULTS \\ Interrater Reliability
}

The Pearson's correlation coefficients showed consistency between graders for all the teeth in each of the four groups. In each case, $r>0.87$ and $p<0.001$ (see Table 1); demonstrating a high correlation between the raters. This permitted calculation of an average rating for each tooth.

\section{Leakage}

None of the negative controls showed any leakage and all of the positive control showed leakage the entire length of the root. Of the 86 specimens starting the study 4 did not clear properly and were excluded from the study leaving a total of 82 . In the iRoot SP group, the mean apical leakage in group A was $0.83 \mathrm{~mm}+/-0.15$, and $0.63 \mathrm{~mm}+/-0.13$ for group $C$. In the $\mathrm{AH}$ Plus group, the mean apical leakage was $1.63 \mathrm{~mm}+/-0.13$ in group $B$, and $0.42 \mathrm{~mm}+/-$ 0.14 in group D. Table 2 and Figures 1 and 2 summarize the mean values for linear dye penetration for the four groups. The test groups were subjected to an analysis of variance shown in Table 3. The test did show that one of the groups was significantly different from the others. The Tukey's HSD (Honestly Significant Difference) test was performed to find the group that was different (Table 2). There were no significant differences between groups A, C, and D. There was significant more apical leakage in group B when compared to all other groups. Values of each group by grader are shown in Figures 3, 4, 5 and 6. 


\begin{tabular}{|llll|}
\hline \multicolumn{4}{|c|}{ Table 1- Pearson Correlation Coeffecient } \\
Variable & by Variable & Correlation & Significant Prob \\
\hline Grader 2 & Grader 1 & 0.8740 & $<.0001$ \\
Grader 3 & Grader 1 & 0.8888 & $<.0001$ \\
Grader 3 & Grader 2 & 0.9303 & $<.0001$ \\
\hline
\end{tabular}


Figure 1- Mean Value of Linear Dye Penetration

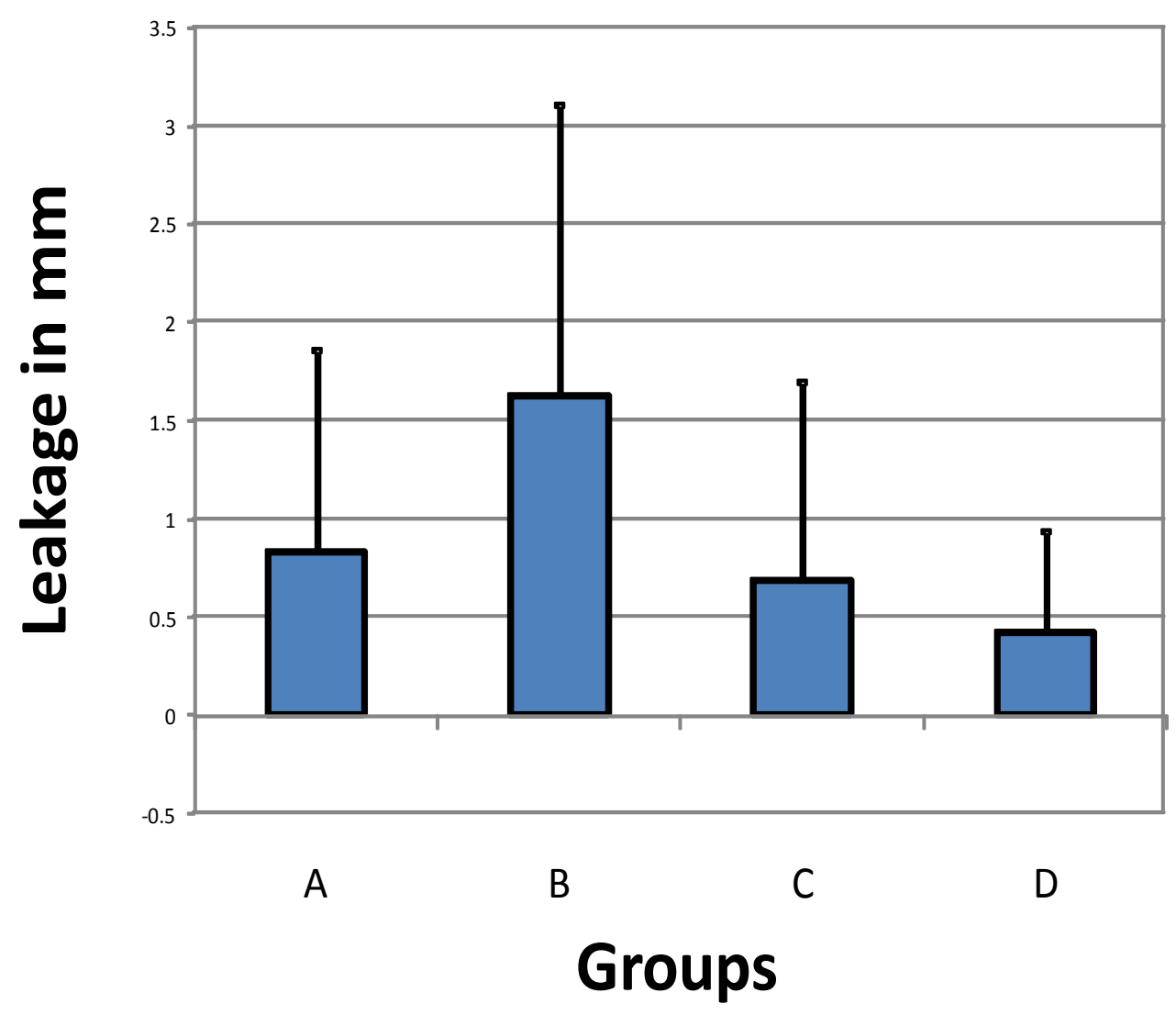


Figure 2- Mean Value of Linear Dye Penetration

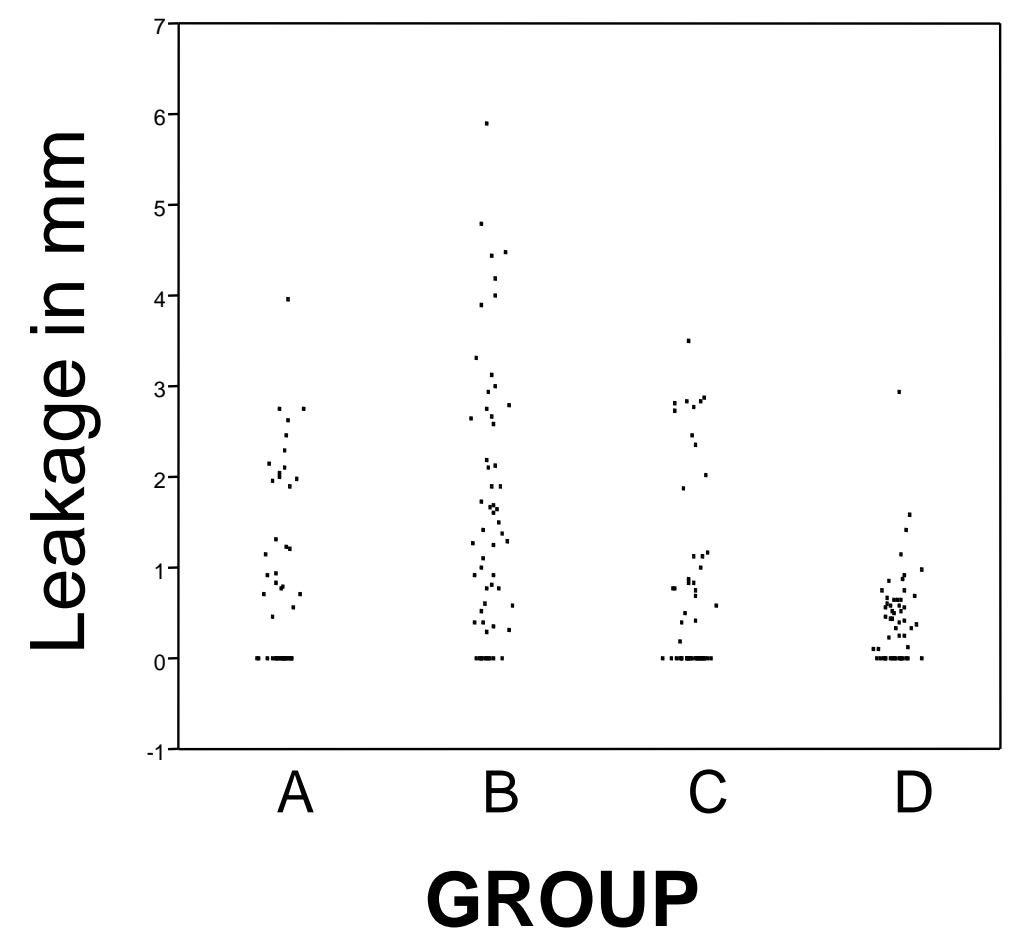




\begin{tabular}{|cccc|}
\hline \multicolumn{4}{c|}{ Table 2- Tukey's Honestly Significant Difference } \\
Group & Mean(score) & Standard Deviation & Tukey result \\
\hline A & 0.83 & 1.03 & $y$ \\
B & 1.63 & 1.48 & $\mathrm{z}$ \\
C & 0.68 & 1.01 & $y$ \\
D & 0.42 & 0.52 & $y$ \\
\hline
\end{tabular}




\section{Table 3- ANOVA}

Source Nparm DF Sum of F Ratio Prob $>F$ Squares

$\begin{array}{llllll}\text { GROUP } & 3 & 3 & 47.941857 & 13.8542 & <.0001\end{array}$ * 


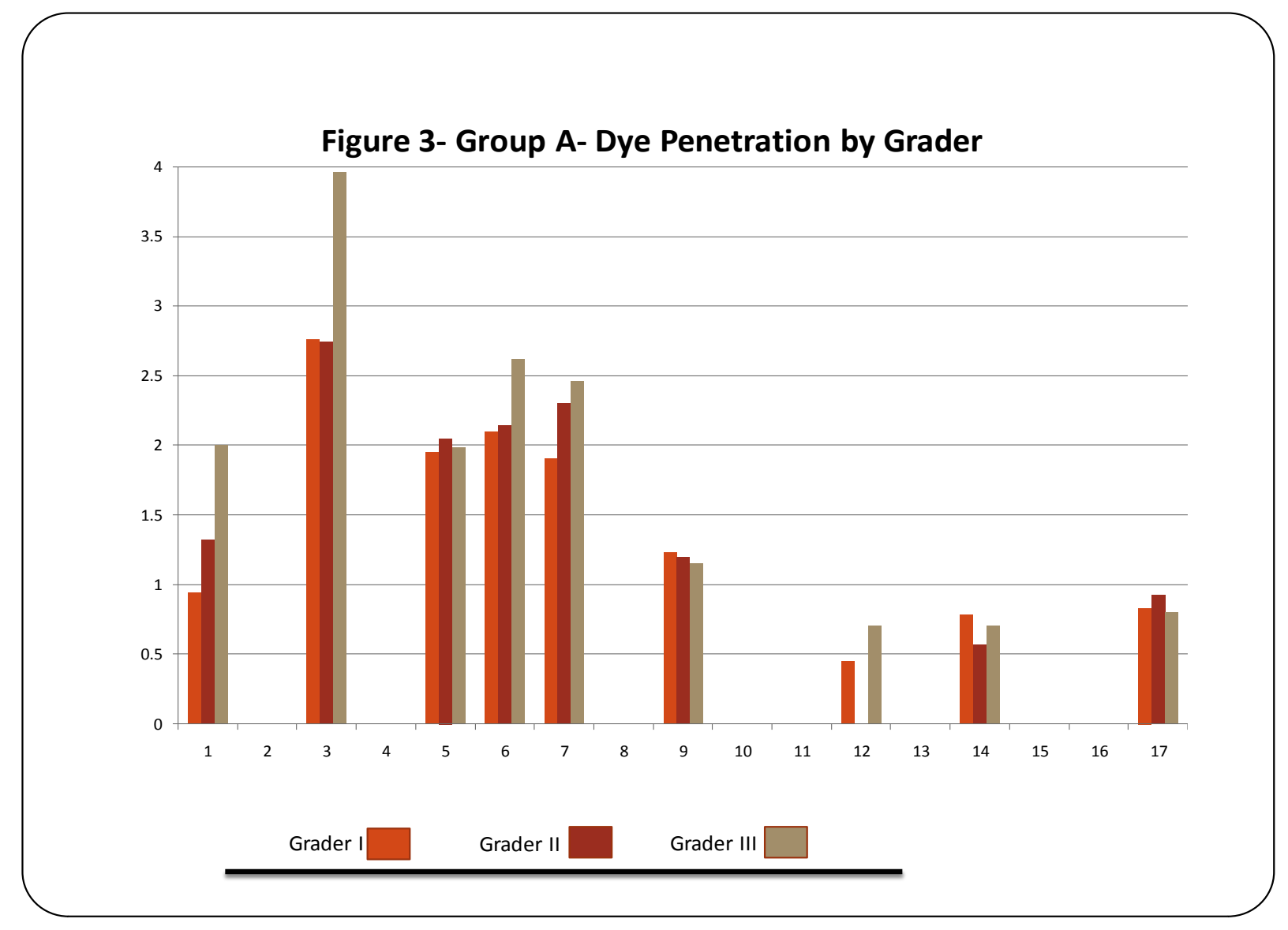


Figure 4- Group B- Dye Penetration by Grader

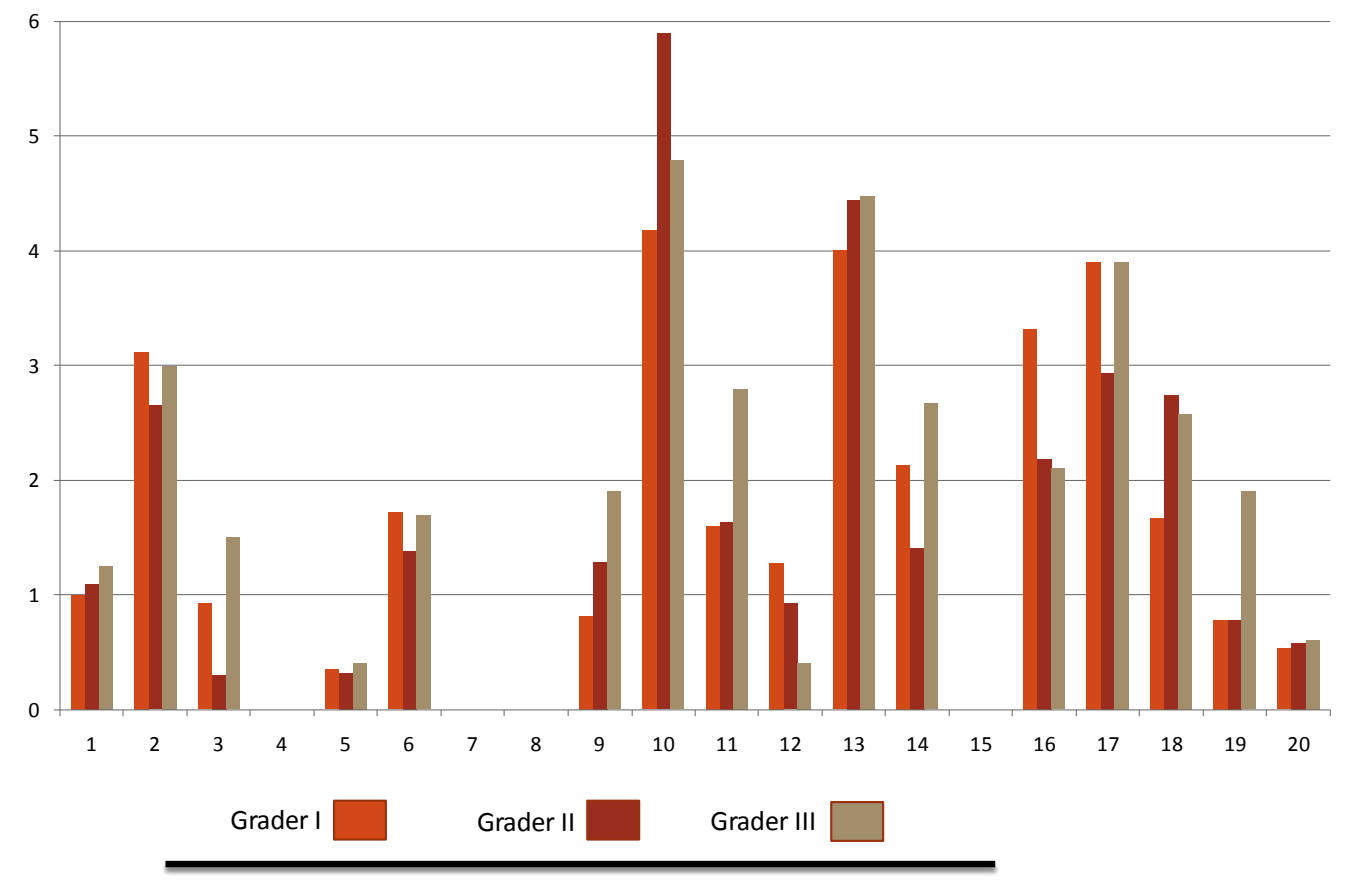




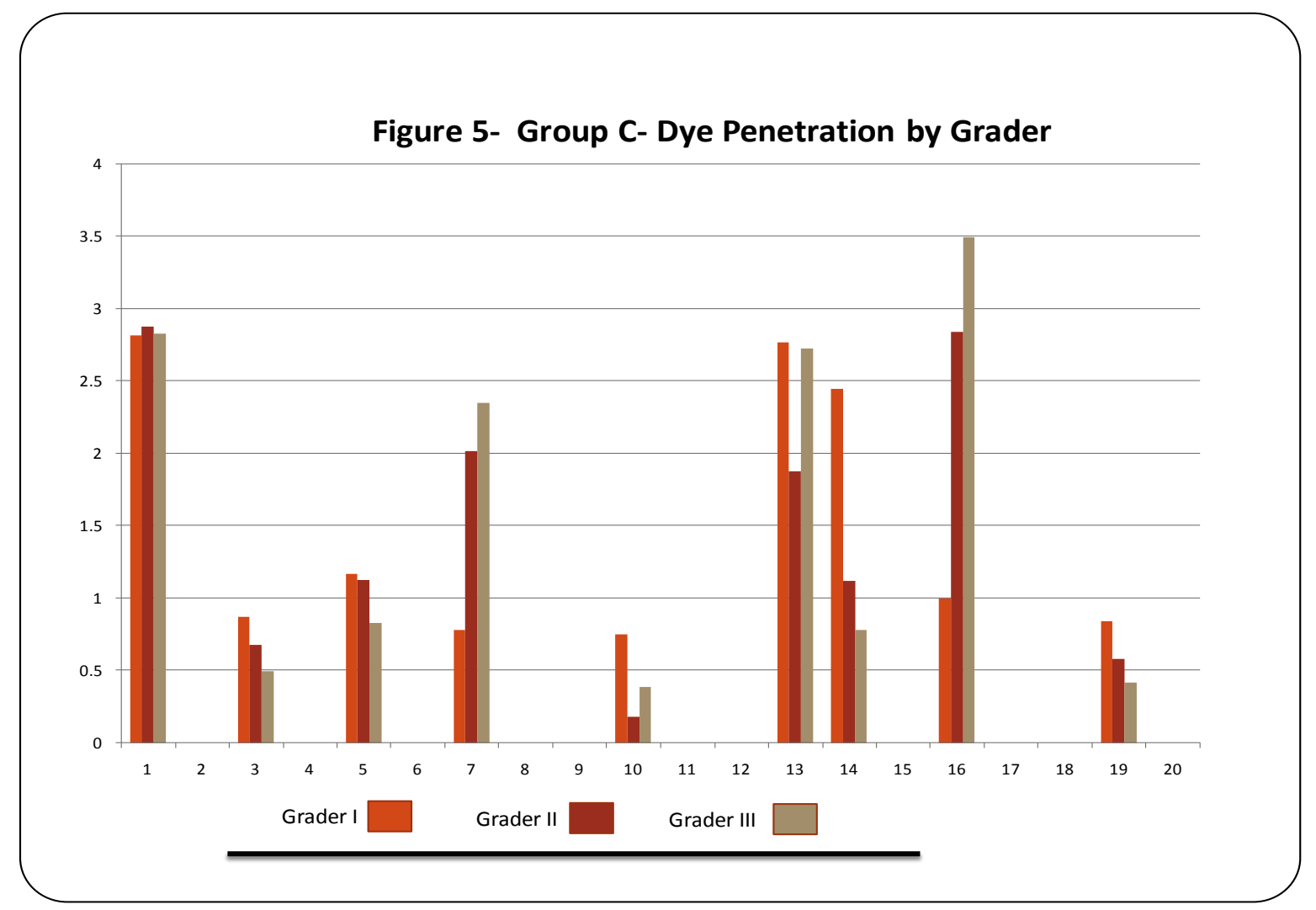




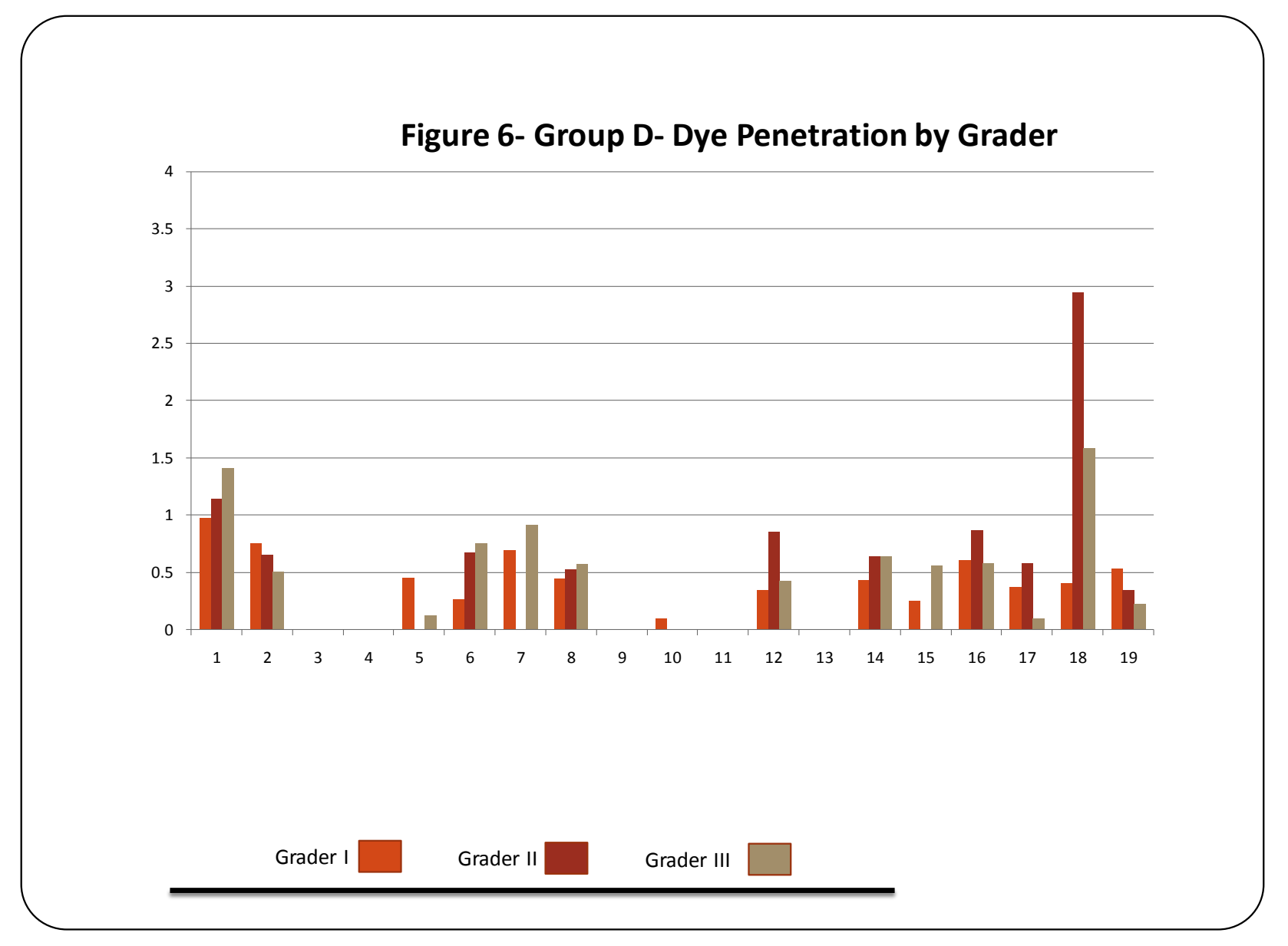




\section{DISCUSSION}

In vitro dye leakage studies have been criticized because mean leakage values are derived from a range of measurements with results and conclusions frequently inconsistent between studies. Differences may be attributed to variations in specimens, testing procedures, instrumentation/obturation techniques and leakage interpretations. One advantage of in vitro testing is that it provides a reasonable method for technique examination and observation without the many restrictions found in a clinical setting. Conversely, it is difficult, if not impossible, for in vitro studies to reproduce clinical conditions. Conclusive evidence regarding efficacy should be drawn from many studies conducted by independent investigators looking at similar technique aspects and from history of clinical use.

The present study was designed to evaluate in vitro apical leakage in root canals prepared in the identical manner utilizing two different sealers (AH Plus, iRoot SP) and two different obturation techniques( Single Cone, Lateral Condensation). Comparable levels of apical leakage were found between iRoot SP (single cone and lateral compaction) and AH plus single cone. AH plus with lateral compaction had statistically more apical dye leakage that the other groups. None of the negative controls showed any leakage and all of the positive controls demonstrated leakage supporting the experimental design.

Prepared root canals are by conventional standards, filled with a solid core material in the presence of an endodontic sealer. The long-term seal provided by such root fillings has been considered to be essential to clinical success. Sealers can fill in fins, apical deltas, and lateral canals, thus improving the sealing ability of gutta percha (71). Unfortunately, all sealers 
suffer physical short-comings such as shrinkage and solubility. These undesirable characteristics are incompatible with long-term sealing efficacy. If dissolution occurs either at the interface between the gutta-percha and the dentin or between the individual gutta percha points, leakage is possible in the space previously occupied by sealer (72). The objective of obturation is to minimize the amount of sealer thickness while maximizing the amount of guttapercha occupying the canal. Gordon et al (33) reported a similar percentage of gutta-percha filled areas when they filled curved canals first using .06 tapered rotary instrumentation followed by either SC or LC techniques. Horsted-Bindslev et al. (73) reported that the LC technique did not differ from the SC technique regarding the radiographic quality of the root fillings. Wu et al. reported the LC and SC in small curved canals had the same radiographic density and fluid transport measurements (74). Tasdemir et al. (75) found that the SC technique produced a significantly greater percentage of gutta-percha-filled area than LC technique at the $2 \mathrm{~mm}$ from apex, but there was no significant difference $4 \mathrm{~mm}$ from the apex with either technique.

AH plus was used in this study as the control sealer because of its known low solubility. Schafer and Zandbiglari, (76) compared the solubility of resin-, silicone-, calcium hydroxide-, zinc oxide- eugenol-, and glass ionomer-based sealers in water and artificial saliva, and reported that AH Plus lost the least amount of weight of all sealers tested in all liquids. Nagas et al (77) suggested that AH Plus may be preferable to EndoRez and Ketac- Endo regarding improved sealing and bonding of the obturation. Both of those studies concluded that the type of sealer can influence the quality of obturation. 
Recently, single cone obturation methods that match the geometry of rotary instruments have been marketed for obturation of the prepared root canal. Use of a single cone can accelerate the obturation process, and at the same time, decrease the lateral forces on the root and possibly decrease the chance of iatrogenic vertical root fracture (78). The single cone with sealer combination results in a uniform mass which avoids the gaps associated with placement of several accessory cones in the LC technique(78). Gutta-percha cones and corresponding rotary instruments must be well matched for an optimal adaptation.

Some studies have concluded that SC suffers higher levels of apical leakage when compared to WVC, LC, and Thermafil techniques. Pommel and Camps (79) compared SC, LC, WVC, Thermafil, and System B techniques with a zinc oxide-eugenol-based sealer and reported that the SC technique had the most leakage. Monticelli et al. (80) compared two contemporary SC techniques with the WVC technique and found the WVC had a more durable apical seal. Yucel and Ciftci (81) concluded that the poor seal with SC may be related to the technique itself, because the gutta-percha is not compacted but it is only inserted to the working length with a substantial amount of sealer.

In contrast, Wu et al. (82) studied the leakage of single cone fillings using a siliconebased sealer for 1 year and concluded that SC fillings prevented fluid transport for that period. Antonopoulos et al. (83) and Yilmaz et al. (84) compared apical leakage in root canals filled with LC and SC technique and reported no difference between the two. Inan et al (85) compared the apical sealing ability of SC, LC, and Thermafil techniques and also found no difference. 
The experimental group studied using the currently accepted technique of LC and AH Plus $^{\circledR}$ was the only group that demonstrated statistically significant more apical dye penetration. This was in direct contrast to the studies performed by Onay et al. (86) and Raina et al. (87) which compared LC of gutta percha and AH Plus against LC of resilon and epiphany and found no significant difference in apical leakage in the experimental groups.

All groups included in the present study were obturated together and group C (AH Plus ${ }^{\circledR}$ with LC) was the last group to be instrumented and obturated. A better approach may have been to randomly assign all specimens so that treatment times varied with in groups. This may have reduced operator fatigue which could have adversely affected results. 


\section{CHAPTER V}

\section{CONCLUSION}

The presents study indicated that single cone obturation with either iRoot $\mathrm{SP}^{\circledR}$ or $\mathrm{AH}$ Plus ${ }^{\circledR}$ have equal or better prevention of apical dye penetration than lateral condensation with the same sealers. Although the clinician should examine many studies and rely on clinically proven methods before choosing one technique or material over another, it seems logical to place value in a technique or material which has been shown to provide a good apical seal invitro. Further studies may be necessary to evaluate the in-vivo success of cases which have been obturated in this manner. Also, of prime consideration, it must be remembered that Trope and Swartz concluded that the quality of the coronal seal is equally important to the outcome of endodontic therapy as the apical seal. The apical seal may be a temporary barrier to invading microorganisms being introduced into the periapex since sealers commonly used

can dissolve over time. Regardless of which obturation technique is employed, the coronal seal must maintain a seal against invading microorganisms into the root canal that was disinfected during endodontic therapy.

All groups tested had similar apical sealing abilities, with the exception being AH Plus ${ }^{\circledR}$ LC group which demonstrated the most apical dye penetration. This in vitro study supports the use of the sealers $\mathrm{AH}$ Plus ${ }^{\circledR}$ or iRoot $\mathrm{SP}^{\circledR}$ in combination with .06 taper gutta percha points in the obturation of .06 canal preparations. 


\section{$\underline{\text { REFERENCES }}$}

1. Dow,P.R. and Ingle, J.I. Isotope determination of root canal failure. Oral Surg. 8:1100-4, 1955.

2. Ingle, John I. and Jerry F. Taintor. Endodontics. $3^{\text {rd }}$ ed. Philadelphia: Lea \& Febiger, 1985; 36.

3. Weine, F.S. Endodontic Therapy. $4^{\text {th }}$ ed. St. Louis: CV Mosby, 1989: 13.

4. Walton,R.E. and Torabinejad,M. Principles and Practice of Endodontics. $1^{\text {st }}$ ed. Philadelphia: W.B. Saunders, 1989; 236.

5. Taintor, J.F. and Ross, P.N. Opinions and practices of American endodontic diplomats. Dent. J. 44:321-5, 1978.

6. Rhome, B.H., et al. Isotopic evaluation of the sealing properties of lateral condensation, vertical condensation, and Hydron. J. Endod. 7:458, 1981.

7. Director, R. C., et al. The short-term sealing properties of lateral condensation, vertical condensation, and Hydron using 14C human serum albumin. J. Endod. 8:149,1982.

8. Russin, T.P., et al. Apical seals obtained with laterally condensed, chloroform-softened gutta-percha and laterally condensed gutta-percha and Grossman's sealer. J. Endod. 6:678-82, 1980.

9. Evans, J.T. and Simon, J.H.S. Evaluation of the apical seal produced by injected thermoplasticized gutta-percha in the absence of smear layer and root canal sealer. J. Endod. 12:101, 1986.

10. Haas, S.B., et al. A comparison of four root canal filling techniques. J. Endod. 15:596601, 1989.

11. Lares, C. and El Deeb, M.E. The sealing ability of the Thermafil obturation technique. J. Endod. 16:474-9, 1990.

12. Skinner, R.L. and Van Himel, T. The sealing ability of injected molded thermoplastized gutta-percha with and without the use of sealer. J. Endod. 13:315-7, 1987.

13. Marshall, F.J., and Massler, M. Sealing of pulpless teeth evaluated with radioisotopes. J. Dent. Med. 16:172,1961.

14. Kapsilmalis, P. and Evans, R. Sealing properties of endodontic filling materials using radioactive polar and nonploar isotopes. Oral Surg. 22:286, 1966.

15. Davis MS, et al. Periapical and intracranial healing following incomplete root canal fillings in dogs. Oral Surg. Oral Med. Oral Path. 31:662-75, 1971. 
16. Sjogren U, Sundqvist G. Bacteriological evaluation of ultrasonic root canal instrumentation. Oral Surg. Oral Med. Oral Path. 63:366-70, 1987.

17. Swartz, DB, et al. Twenty years of endodontic success and failure. J. Endod. 9:198-202, 1983.

18. Ingle Jl. Existos y Francasos en Endodoncia. Revista de la Asociacion Odontologica Argentina. 2:50:67, 1962.

19. Barbakow, F.H., et al. An evaluation of 566 cases of root canal therapy in general dental practice.2. postoperative observations. J. Endod. 6:485-89, 1980.

20. Morse, D.R., et al. A radiographic evaluation of the periapical status of teeth treated by the gutta-percha-eucapercha endodontic method: A one year follow-up study of 458 root canals. Part III. Oral Surg. Oral Med. Oral Path. 56:190-7, 1983.

21. Ray, Ha, Trope, M. Pericapical status of endodontically treated teeth in relation to the technical quality of the root filling and the coronal restoration. Int Endo J. 28:12-18, 1995.

22. Wong, $M$ et al. Comparison of gutta-percha filling techniques, compaction(mechanical), vertical(warm), and lateral condensation techniques, part I. J. Endod. 7:551-58, 1981.

23. Dalat, D.M., Spangberg, L.S.W. Comparison of apical leakage in root canals obturated with various gutta-percha techniques using a dye vacuum tracing method. J. Endod. 20:315, 1994.

24. Qualtrough AJE, Whitworth JM, Dummer PMH. Preclinical endodontology: an international comparison. Int Endod J 1999;32:406 -14.

25. Ingle JI, Himel Van T, Hawrish CE, et al. Endodontic cavity preparation. In: Ingle JI, Bakland LK eds. Endodontics, 5th ed. London: BC Decker Inc; 2002:405-570.

26. Beatty RG. The effect of standard or serial preparation on single cone obturations. Int Endod J 1987;20:276-81.

27. Hommez GMG, de Moor RJG, Braem M. Endodontic treatment performed by Flemish dentists. Part 2. Canal filling and decision making for referrals and treatment of apical periodontitis. Int Endod J 2003;36:344 -51.

28. Dummer PMH. Root canal filling. In: Pitt Ford TR ed. Harty's Endodontics in clinical practice, 5th ed. Edinburgh: Wright; 2004:113-42. 
29. Beer R, Gängler $P$, Beer $M$. In-vitro-Untersuchungen unterschiedlicher Wurzelkanalfülltechniken und materialen. Zahn Mund Kieferheilk 1986;74:800-6.

30. Wu M-K, van der Sluis LWM, Ardila CN, Wesselink PR. Fluid movement along the coronal two-thirds of root fillings placed by three different gutta-percha techniques. Int Endod J 2003;36:533-40.

31. Zmener O, Pameijer $\mathrm{CH}$, Macri E. Evaluation of the apical seal in root canals prepared with a new rotary system and obturated with a methacrylate based endodontic sealer: an in vitro study. J Endod 2005;32:392-5.

32. ElAyouti A, Achleithner C, Löst C, Weiger R. Homogeneity and adaptation of a new gutta-percha paste to root canal walls. J Endod 2005;9:687-90.

33. Gordon MPJ, Love RM, Chandler NP. An evaluation of. 06 tapered gutta-percha cones for filling of. 06 taper prepared curved root canals. Int Endod J 2005;38:87-96.

34. Friedman S, Löst C, Zarrabian M, Trope M. Evaluation of success and failure after endodontic therapy using a glass ionomer cement sealer. J Endod 1995;21:384 -90.

35. Portenier I, Lutz F, Barbakow F. Preparation of the apical part of the root canal by the lightspeed and step-back techniques. Int Endod J 1998;31:103-11.

36. Kosa DA, Marshall G, Baumgartner JC. An analysis of canal centering using mechanical instrumentation techniques. J Endod 1999;25:441-5.

37. Gluskin AH, Brown DC, Buchanan LS. A reconstructed computerized tomographic comparison of Ni-Ti rotary GTTM files versus traditional instruments in canals shaped by novice operators. Int Endod J 2001;34:476-84.

38. Perez F, Schoumacher M, Peli JF. Shaping ability of two rotary instruments in simulated canals: stainless steel ENDOflash and nickel-titanium HERO Shaper. Int Endod J 2005;38:637-44.

39. Tasdemir T, Aydemir H, Inan $U, U$ “ nal O. Canal preparation with Hero 642 rotary Ni-Ti instruments compared with stainless steel hand K-file assessed using computed tomography. Int Endod J 2005;38:402-8.

40. Glosson CR, Haller RH, Dove SB, del Rio CE. A comparison of root canal preparations using $\mathrm{Ni}$-Ti hand, $\mathrm{Ni}-\mathrm{Ti}$ engine-driven, and $\mathrm{K}$-flex endodontic instruments. J Endod 1995;21:146-51. 
41. Peters OA, Schönenberger K, Laib A. Effects of four Ni-Ti preparation techniques on root canal geometry assessed by micro computed tomography. Int Endod J 2001;34:221-30.

42. Hembrough MW, Steiman HR, Belanger KK. Lateral condensation in canals prepared with nickel titanium rotary instruments: an evaluation of the use of three different master cones. J Endod 2002;28:516 -9.

43. Gillespie WT, Loushine RJ, Weller RN, et al. Improving the performance of EndoREZ root canal sealer with a dual-cured two-step self-etch adhesive. II. Apical and coronal seal. J Endod 2006;32:771-5.

44. Grossman, L., Oliet, S., and Ddel rico, C. Endodontic Practice. $11^{\text {th }}$ ed. Philadelphia: lea \& Febiger, 1988; 255.

45. Branstetter, J. and Von Fraunhofer, J.A. The physical properties and sealing action of endodontic sealer cements: a review of the Literature. J. Endod. 8:312-16,1982.

46. Zhang, H., Shen,Y., Ruse,D.,Haapasalo,M. Antibacterial activity of endodontic sealers by modified contact test against Enterococcus faecalis. J. Endod. 35:1051-55, 2009.

47. Fransen JN, He J, Glickman GN et al(Baylor Univ.). Comparative Assessments of Active GP/Glass Ionomer Sealer, Resilon/Epiphany and Gutta-Percha/AHPlus Obturation: A Bacterial Leakage Study.

48. Zhang,W., Li,Z., Peng,B. Assessment of a new root canal sealer's apical sealing ability. Oral Surg. Oral Med. Oral Path. Oral Radiol. Endod 2009;107:e79-e82.

49. Kokubo T, ed. Bioceramics and Their Clinical Applications. Great Abington, Cambridge, England: Woodhead Publishing Ltd; 2008.

50. Best SM, Porter AE, Thian ES, et al. Bioceramics: past, present and for the future. J European Ceramic Society. 2008;28:1319-1327.

51. Dubok VA. Bioceramics-yesterday, today, tomorrow. Powder Metallurgy and Metal Ceramics. 2000;39:381-394.

52. Hench LL. Bioceramics: from concept to clinic. J Am Ceram Soc. 1991;74:1487-1510.

53. Torabinejad M, Hong CU, McDonald F, et al. Physical and chemical properties of a new root-end filling material. J Endod. 1995;21:349-353. 
54. Beatty, RG, et al. The efficacy of four root canal obturation techniques in preventing apical dye penetration. J Am Dent Assoc 1989:119:633-7.

55. Goodell, GG, et al. Linear dye penetration of a calcium phosphate cement apical barrier. J Endod 1997; 23:174-7.

56. Dow, PR, Ingle, Jl. Isotope determination of root canal failure. Oral Surg 1955;8:1100-4.

57. Fuss, Z, et al. Comparative sealing quality of gutta-percha following the use of the McSpadden Compactor and the Engine Plugger. J Endod 1985; 11:117-121.

58. Mattison, GD, von Fraunhofer, JA. Electrochemical microleakage study of endodontic sealer cements. Oral Surg 1983;55:402-7.

59. Torabinejad, $M$, et al. In vitro bacterial penetration of coronally unsealed endodontically treated teeth. J Endod 1990;16:566-69.

60. Ainley, JA. Fluorometric assay of the apical seal of root canal fillings. Oral Surg Oral Med Oral Path 1970; 29:753-62.

61. Torabinejad, $M$, et al. Scanning electron microscopic study of root canal obturation using thermoplastized gutta-percha. J Endod 1978; 4:245-50.

62. Matloff, IR, et al. A comparison of methods used in root canal sealability studies. Oral Surg 1982; 53: 203-8.

63. Goldman, $M$, et al. The usefulness of dye-penetration studies reexamined. Oral Surg, Oral Med, Oral Path 1989; 67: 327-32.

64. Spangberg, LS, et al. Influence of entrapped air on the accuracy of leakage studies using dye penetration methods. J Endod 1989; 15: 548-51.

65. Kersten, HW, Moorer, WR. Particles and molecules in endodontic leakage. Int Endo Jrnl 1989; 22: 118-124.

66. Dumsha T, Hovland EJ. Evaluation of long-term calcium hydroxide treatment in avulsed teeth- and in vivo study. Int Endo Jrnl 1995; 28: 7-11.

67. Eldeeb, ME, et al. Apical leakage in relation to radiographic density of gutta-percha using different obturation techniques. J Endod 1985; 11: 25-9.

68. Hopkins, Jh, et al. McSpadden versus lateral condensation: the extent of apical microleakage. J Endod 1986; 12: 198-201. 
69. Robertson, DC, Leeb, IJ. The evaluation of a transparent tooth model system for the evaluation of endodontically filled teeth. J Endod 1982; 8: 317-321.

70. Roda, RS, Gutmann, JL. Reliability of reduced air pressure methods used to assess the apical seal. Int Endo Jrnl 1995; 28:154-162.

71. Wu MK, Fan B, Wesselink PR. Diminished leakage along root canals filled with guttapercha without sealer over time: a laboratory study. Int Endod J 2000;33:121-5.

72. Kontakiotis EG, Wu MK, Wesselink PR. Effect of sealer thickness on long-term sealing ability: a 2-year-follow-up study. Int Endod J 1997;30:307-12.

73. Horsted-Bindslev P, Andersen MA, Jensen MF, Nilsson JH, Wenzel A. Quality of molar root canal fillings performed with lateral compaction and the single-cone technique. J Endod 2007;33:468-71

74. Wu MK, Bud M, Wesselink P. The quality of single cone and laterally compacted guttapercha fillings in small and curved root canals as evidence by bidirectional radiographs and fluid transport measurements. Oral Surg Oral Med Oral Pathol Oral Radiol Endod 2009;108:946-951.

75. Tasdemir T, Yesilyurt C, Ceyhanli KT, Celik D, Er K. Evaluation of apical fillings after root canal fillings by 2 different techniques. J Can Dent Assoc 2009;75:201-201d.

76. Schafer E, Zandbiglari T. Solubility of root canal sealers in water and artificial saliva. Int Endod J 2003;36:660-9.

77. Nagas E, Altundasar E, Serper A. The effect of master point taper on the bond strength and apical sealing ability of different root canal sealers. Oral Surg Oral Med Oral Pathol Oral Radiol Endod 2009;107:e61-4.

78. Gomes BP, Pinheiro ET, Sousa EL, Jacinto RC, Zaia AA, Ferraz CC, et al. Enterococcus faecalis in dental root canals detected by culture and by polymerase chain reaction analysis. Oral Surg Oral Med Oral Pathol Oral Radiol Endod 2006;102:247-53.

79. Pommel L, Camps J. In vitro apical leakage of system B compared with other filling techniques. J Endod 2001;27:449-51.

80. Monticelli F, Sadek FT, SchusterGS, Volkmann KR, Looney SW, Ferrari M, et al. Efficacy of two contemporary single-cone filling techniques in preventing bacterial leakage. J Endod 2007;33:310-3. 
81. Yucel AC, Ciftci A. Effects of different root canal obturation techniques on bacterial penetration. Oral Surg Oral Med Oral Pathol Oral Radiol Endod 2006;102:e88-e92.

82. Wu MK, van der Sluis LW, Wesselink PR. A 1-year follow-up study on leakage of singlecone fillings with RoekoRSA sealer. Oral surg Oral Med Oral Pathol Oral Radiol Endod 2006;101:662-7.

83. Antonopoulos KG, Attin T, Hellwig E. Evaluation of the apical seal of root canal fillings with different methods. J Endod 1998;24:655-8.

84. Yilmaz Z, Tuncel B, Ozdemir HO, Serper A. Microleakage evaluation of roots filled with different obturation techniques and sealers. Oral Surg Oral Med Oral Pathol Oral Radiol Endod 2009;108:124-8.

85. Inan U, Aydin C, Tunca YM, Basak F. In vitro evaluation of matched-taper single-cone obturation with a fluid filtration method. J Can Dent Assoc 2009;75:123-6.

86. Onay $E$, Ungor $M$, Orucoglu $H$. An in vitro evaluation of the apical sealing ability of a new resin-based root canal obturation system. J Endod 2006;33:976-978.

87. Raina R, Loushine R, Weller R, Tay F,Pashley. Evaluation of the quality of the apical seal in Resilon/Epiphany and gutta-percha/AH Plus-filled root canals by using a fluid filtration approach. J Endod 2007;33:944-947. 